\title{
Clinical and Epidemiological Data of COVID-19 from Regensburg, Germany - A Retrospective analysis of 1084 consecutive cases
}

Benedikt M J Lampl ( $\sim$ benedikt.lampl@lra-regensburg.de )

Public Health Department/University of Regensburg

Matthias Buczovsky

Public Health Department Regensburg

Gabriele Martin

Public Health Department Regensburg

Helen Schmied

Public Health Department Regensburg

Michael Leitzmann

Department of Epidemiology and Preventive Medicine, Faculty of Medicine, University of Regensburg, Germany

Bernd Salzberger

Department of Infection Control and Infectious Disease, University of Regensburg, Germany

\section{Research Article}

Keywords: COVID-19, Epidemiology, Symptom Duration, Risk Factors, Infection Control

Posted Date: November 6th, 2020

DOl: https://doi.org/10.21203/rs.3.rs-103516/v1

License: (c) (1) This work is licensed under a Creative Commons Attribution 4.0 International License. Read Full License

Version of Record: A version of this preprint was published at Infection on March 5th, 2021. See the published version at https://doi.org/10.1007/s15010-021-01580-2. 


\section{Clinical and Epidemiological Data of}

2 COVID-19 from Regensburg, Germany - A

3 Retrospective analysis of 1084 consecutive

4 cases

5

6

7

8

9

Benedikt MJ Lampl ${ }^{1}$, Matthias Buczovsky ${ }^{1}$, Gabriele Martin ${ }^{1}$, Helen Schmied ${ }^{1}$, Michael Leitzmann², Bernd Salzberger ${ }^{3}$

${ }^{1}$ Public Health Department Regensburg, Germany/ University of Regensburg, Germany

${ }^{2}$ Department of Epidemiology and Preventive Medicine, Faculty of Medicine, University of Regensburg, Germany

${ }^{3}$ Department of Infection Control and Infectious Disease, University of Regensburg, Germany

\section{Corresponding Author:}

Dr. Benedikt Lampl

Gesundheitsamt Regensburg

Division of Infection Control

Altmühlstr. 3

93059 Regensburg, Germany

Phone: +49941 4009523

Mail: benedikt.lampl@Ira-regensburg.de 


\section{Abstract}

Background: COVID-19 is a new syndrome caused by the recently emerged SARS-CoV-2. We collected clinical and epidemiologic data in an almost complete cohort of SARS-CoV-2 positive individuals from Regensburg, Germany, from March 2020 to May 2020.

Methods: Retrospective cohort of consecutive COVID-19 cases recorded between March 7, 2020 and May 24, 2020 as part of an infection control investigation program, with prospective follow-up interviews gathering information on type and duration of symptoms and COVID-19 risk factors until June 26, 2020.

Results: Of 1,089 total cases, 1,084 (99.6\%) cases were included. The incidence during the time period was $315.4 / 100,000$, lower than in the superordinate government district Oberpfalz $(468,5 / 100,000)$ and the overall state of Bavaria $(359.7 / 100,000)$. The case fatality rate was $2.1 \%$. Among fatal cases, the mean age was 74.4 years and $87 \%$ presented with known risk factors, most commonly chronic heart disease, chronic lung disease, kidney disease, and diabetes mellitus. 897 cases (82,7\%) showed at least one symptom, most frequently cough (45\%) and fever (41\%). Further, $18 \%$ of cases suffered from odour/taste disorder. $17 \%$ of total cases reported no symptoms. The median duration of general illness was 10 days. During follow-up, 8,9\% of 419 interviewed cases reported at least one symptom lasting at least 6 weeks, and fatigue was the most frequent persistent symptom.

Discussion: We report data on type and duration of symptoms, and clinical severity of nearly all $(99,5 \%)$ patients with SARS-CoV-2 recorded from March 2020 to May 2020 in Regensburg. A broad range of symptoms and symptom duration was seen, some of them lasting several weeks. The case fatality rate was $2.1 \%$. Asymptomatic cases may be underrepresented due to the nature of the study.

Key Words: COVID-19 - Epidemiology - Symptom Duration - Risk Factors - Infection Control. 


\section{Introduction}

In November 2019, a novel corona virus (SARS-CoV-2) caused a first outbreak in Wuhan, Hubei, China. Millions of cases of coronavirus disease 2019 (COVID-19) have subsequently been reported from all over the world, with more than a million COVID-associated deaths globally [1, 2].

SARS-CoV-2 can cause severe disease, including pneumonia, acute respiratory distress syndrome (ARDS) and multi-organ failure [3]. On the other hand, $90 \%$ of all known infections are mild or moderate [4]. Known risk factors for severe disease are higher age, hypertension, cardiovascular and chronic pulmonary disease, diabetes, immunodeficiency, smoking, male gender [5]. Children are less often affected than adults [6]. The most frequent symptoms are fever, cough and rhinitis [4]. Data on symptom duration and long-term alterations are incomplete yet.

We present a complete investigation of data on 1,084 consecutive cases of COVID-19 reported in Regensburg. We focus on clinical and epidemiologic data, including frequency and duration of symptoms, risk factors for COVID-19, and characteristics of fatal cases. Information was collected via personal interviews during infection control investigations and follow-up interviews from the first reported case in March 2020 until the end of the wave in May 2020.

\section{Methods}

To study the characteristics and chronology of cases in Regensburg, we employed a retrospective cohort design of 1,084 consecutive COVID-19 cases (by date of reporting) in the city and county of Regensburg, Bavaria from the first reported case on March 7, 2020 through May 24, 2020. The total number of cases in the respective period was 1,$089 ; 5$ cases were not included due to a delay in reporting.

Case definition: We applied the case definition according to criteria put forth by the Robert Koch Institute (RKI), the federal government agency responsible for disease control and prevention [7]. Specifically, any validated new positive result of a SARS-CoV-2 PCR test reported by a laboratory was regarded a case. Only new cases were registered. Suspected cases, individuals with a negative PCR result, and those with serological detection of antibodies only or typical morphological alterations in computed tomography only were not considered cases.

Investigations and infection control measures: All names and contact data of individuals with a SARSCoV-2 positive test result were reported to the Regensburg Public Health Department. Cases were contacted by telephone on the day of reporting and were queried about the type and length of all contacts within the respective period of infectivity ( 2 days before onset of symptoms until diagnosis). 
Cases and close contact persons meeting RKI's definition [8] were quarantined on the basis of the RKI recommendations. Cases were quarantined for at least 14 days from symptom onset.

Data collection: The chronology of cases was depicted as epidemic curve. Case numbers were calculated as incidence per 100.000 per day. During the first peak phase of the SARS-CoV-2 pandemic, data were collected in parallel to infection control and containment measures. A first dataset comprised 1,084 consecutive cases and was compiled using a telephone interview, during which information was collected on age, sex, symptoms (fever, cough, rhinitis, headache, fatigue, limb pain, shivering, sore throat, dyspnoea, odour or taste disorders, nausea and diarrhoea), exposure, hospitalisation, and the presence of COVID-19 risk factors (chronic lung disease, asthma, chronic heart disease, diabetes, immunosuppression, neuromuscular disease, pregnancy).

A second dataset was obtained using an additional telephone interview in a sub-sample of 419 of the 1,084 original cases we were able to contact by phone. Cases were eligible for phone calls when at least 6 weeks after the onset of symptoms had passed. Interviews were performed between June 1, 2020 and June 26, 2020 and gathered additional information on the type and duration of symptoms, and possible risk factors. Due to limited resources, only one attempt was made to contact cases by phone.

Informed consent for anonymized data collection was provided by all participants. After the data collection was completed, all data were completely anonymized and analyzed. The study protocol was approved by the ethics committee of the University of Regensburg (Nr. 20-2067-104).

Statistical Analysis: All statistical analyses were conducted using non-parametric methods. In particular, we tested whether the median value differed between groups using the Wilcoxon rank-sum test. All analyses were performed using Microsoft Excel 2016 and the statistical software R 3.6.2.

\section{Results}

A total of 1089 cases were reported to the Public Health Department Regensburg between March 7, 2020 (date of report of the first case in Regensburg, symptom onset on February 2, 2020) and May 24, 2020. Overall, an incidence of 315.4 cases $/ 100,000$ was noted during that time period (Fig. 1 ). The mean incidence per day in the considered period was 4.0 cases per 100,000. Furthermore, fatal cases are shown by date of death as absolute numbers. The shown numbers represent only cases of persons resident within the city or county of Regensburg.

The epidemic curve shows a steady increase in cases throughout the beginning of April 2020, with a peak incidence of 14.2 cases per 100,000 on April 1, 2020. Subsequently, the number of new cases decreased in a stepwise fashion until the second half of May. Peak numbers on May 20, 2020 and May 
24, 2020 represent outbreaks in facilities for asylum seekers and were due to intensified testing of contact persons. There were smaller local outbreaks in nursing homes, asylum seekers' homes, and a major outbreak in the University Children's Hospital (including 36 cases among medical personnel) during the reported time period [9].

\section{Dataset I}

Characteristics of 1084 analysed cases are shown in Table 1.

\section{Exposure}

A total of 470 of 1084 cases (43.4\%) reported having had contact with a SARS-CoV-2-positive person, and 107 cases (9.9\%) indicated having travelled within 14 days prior to symptom onset. 382 cases (35.2\%) worked or lived in healthcare/nursing/childcare/asylum seekers' facilities (institutions according to $\S 23, \S 33$ or $\S 36$ of the German Infection Protection Act [Infektionsschutzgesetz, IfSG]).

\section{Data on age and sex distribution, age-specific attack rates and proportion of hospitalized patients}

Of the 1.084 consecutive patients, the mean age was 43 years, $50 \%$ were female, and $59.3 \%$ were city residents. Fig. $2 \mathrm{~A}$ shows the age and sex distribution of cases in absolute numbers and as a proportion of cases. Approximately seventy percent of cases were reported in patients between 21 and 60 years of age, and $19 \%$ of cases was aged over age 60 years. The proportion of initially asymptomatic persons was $17 \%$ (onset manifestation index: $83 \%$ ). In $13 \%$ of cases, the onset of symptoms could not be determined.

During the study period, a total of 1,842 close contact persons (category I according to RKI, infection suspects) were investigated and quarantined, of which 171 persons tested positive in PCR. This equals an overall secondary attack rate of $9.3 \%$ in our cohort. Fig. 2 B depicts the age-specific attack rates by 10-year age categories. Low attack rates were noted for children, with linearly increasing numbers for those above the age of 60 years. Of 171 cases among close contact persons, 113 (66\%) lived together with a known case in one household. Based on 106 cases (62\%), the mean serial interval was 5,9 d (SD: 4,45; median: $5 \mathrm{~d}$, IQR: 3-8,25 d). The interval from symptom onset to diagnosis was significantly longer in infected close contact persons than in index cases (median 5 versus $7 d ; p<0.00001$ ).

Fig. 2 C depicts hospitalizations of cases in the considered period as officially reported to the Public Health department until 05/10/2020. A total of 154 cases (14.2\%) were hospitalized. There were no reported hospitalizations in the age group 11 to 20 years, whereas the greatest proportion of hospitalizations (69.7\%) were noted in the group aged 81 to 90 years. A linear increase in hospitalizations over time was seen in patients aged 31 to 40 years and those aged 81 to 90 years.

The proportion of initially hospitalized patients was $36 \%$ in patients with dyspnoea, and $13 \%$ in patients without dyspnea. Thus, the relative risk of hospitalization with dyspnea at the time of symptom onset 
was 2.77 compared to patients without dyspnea. The frequency of initial hospitalization was $24 \%$ when risk factors were present, and $8 \%$ when they were absent. This corresponds to a threefold increased relative risk of hospitalization in the presence of risk factors.

\section{Fatal cases}

23 COVID-19-related deaths occurred in the reported period (characteristics shown in Table 1). Based on a total of 1,084 cases, this equals a case fatality rate (CFR) of $2.1 \%$ for the city / county of Regensburg. There were twice as many fatal cases among men than women (15 [65.2\%] vs. 8 [34.8\%]). The most frequently reported symptom among fatal cases was cough $(52.2 \%)$, whereas fever and dyspnoea were reported by only $34.8 \%$ of patients. Of 23 fatal cases, $20(87 \%)$ reported having comorbidities or other risk factors, most frequently chronic heart disease, chronic lung disease, diabetes mellitus and kidney disease. Twenty of 23 patients (87\%) were hospitalized. The duration of disease (symptom onset to death) varied considerably (median 12 days, IQR: 2 - 33 days, maximum 59 days).

Data on incidence and fatalities were compared with other regional and international data (Table 2) $[1,10,11,12,13,14,15,16,17,18,19]$. In Regensburg, the incidence was lower than the whole of Oberpfalz and Bavaria. In Tirschenreuth, which was heavily affected, the incidence was five times higher and the CFR was approximately 5,5 times higher than in Regensburg. Fig. 3 shows cases (A) and fatalities (B) of Regensburg, Tirschenreuth, Oberpfalz and Bavaria by age group. In Regensburg, comparably more persons of younger age were affected (20-29 years and 30-39 years), whereas in Tirschenreuth, persons ages 70-79 years and 80-89 years were more frequently affected. Surprisingly, the highest CFR of $43.5 \%$ was noted there in the age group 60-69 years. In Tirschenreuth, younger people aged 20-49 years also died from the disease, whereas in Regensburg fatal cases did not occur below the age of 50 .

\section{Symptoms}

The most common symptoms were cough (45\%) and fever (41\%). By comparison, gastrointestinal symptoms (diarrhoea/vomitus) were seldomly reported (9\%). $18 \%$ of subjects suffered from odour/taste disorder, and 17\% reported no symptoms in the initial interview. Odour/taste disorder occurred with different frequencies across age groups. It was most common in the group aged 31 to 40 years, with a proportion of $27 \%$ of all cases. Fig. 4 shows the frequency of reported symptoms by age group at the time of the first interview. Symptoms were generally less frequently reported in the age group 0-10 years and in those aged over 80 years. Fever appeared to be the leading symptom in all age groups, with cough being less frequently reported in the very young and the very elderly. 


\section{Dataset II}

A total of 419 of 834 eligible patients responded to the telephone interview performed from Juni 1, 2020 to June 26,2020 using a standardized questionnaire.

\section{Frequency and duration of Symptoms}

Results concerning the frequency and duration of symptoms are depicted in Fig. 5 . Of 419 participants, 15 (3.6\%) did not report any symptoms, 3 complained about feeling ill persisting up to the time of the interview, and the status of the remaining patients was unclear. The duration of general illness was determined in 385 cases (Fig. 5 A). The average duration of illness in these patients was 12.7 days (median 10). 50\% of the patients showed a duration of illness between 4 and 17 days (IQR = 13; maximum duration of symptoms reported: 91 days).

In the follow-up interview, fatigue was the most commonly reported symptom, followed by odour/taste disorder and fever. The median duration of symptoms ranged from 2.5 days (diarrhoea) to 12 days (skin changes). The shortest IR (3 to 7.15 days) was observed for pain of the limbs. Fever duration was quite short (median: 4 days, IR: 2 to 7 days), whereas cough lasted considerably longer (median 10 days, IR: 4 to 14 days). All displayed symptoms showed considerable outliers.

A relevant proportion of cases (8.9\%) reported at least one persistent symptom for at least 6 weeks (Fig. 5 B). Odour/taste disorder, difficulty breathing, cough and fatigue were the most common symptoms. Odour/taste disorder was reported by 37 patients (13,5\% of all patients having answered the symptom "yes" or $8.9 \%$ of all patients interviewed). Skin changes occurred rather rarely but lasted longer than six weeks in $15.7 \%$ of persons.

\section{Risk factors}

Data on risk factors and symptoms are shown in Table 3. ACE inhibitor use, smoking, and body mass index (BMI) above $30 \mathrm{~kg} / \mathrm{m}^{2}$ were investigated as risk factors for the presence and duration of symptoms. Of 406 patients who responded to the question on ACE inhibitor use as part of their daily medication (Table 3 A), 21 (5.2\%) took an ACE inhibitor. Eight of 21 patients reporting ACE use reported dyspnea (38\%), whereas 155 of 385 patients not using an ACE inhibitor (39.9\%) reported dyspnoea (RR: 0.95). Of 21 patients identified during follow-up as using an ACE inhibitor, only 6 patients were initially treated in a hospital (first dataset), and all had major comorbidities. When the duration of symptoms in general, cough and difficulty breathing were compared, there were no statistically significant differences in the reported length of symptoms by ACE inhibitor use.

Information on smoking was obtained for 417 cases (Table 3 B), of which 50 patients (12\%) were smokers and 367 (87.8\%) were non-smokers. Among smokers, the RR for difficulty breathing was elevated, whereas the RR for cough was decreased as compared to non-smokers. Odour/taste disorder 
was reported almost equally by smokers and non-smokers (RR for smokers: 0.93). The duration of

213 illness was significantly shorter in smokers than non-smokers $(p=0.0127)$. The median duration of dyspnoea was $3(1-21)$ days in smokers and $7(1-90)$ days in non-smokers $(p=0.0706)$. Also, the reported duration of odour/taste disorder was shorter in smokers than non-smokers (median 6 versus 8 days, $p=0.0182$ ) as was the duration of general illness (median 6 versus 10 days, $p=0.0127$ ).

In patients with a $\mathrm{BMI}>30 \mathrm{~kg} / \mathrm{m}^{2}$, dyspnoea and cough were reported more frequently (RRs: 1,5 and 1,3 , respectively) and the duration of general illness was longer (median 14 versus 10 days), whereas the duration of cough was shorter (median 9 versus 10 days) than in those with a BMI $<30 \mathrm{~kg} / \mathrm{m}^{2}$ (Table 3 C).

\section{Discussion}

Our study represents the first nearly complete investigation of COVID-19 symptoms and disease severity from a major city and county in Eastern Bavaria. It provides important insights into relevant clinical and epidemiologic features of COVID-19. Our results contribute to a more detailed understanding of age-specific characteristics of the disease while confirming data from other regions with respect to demographic characteristics, symptoms and risk factors [20].

The highest incidence was observed on April 1, 2020, exactly one week after further restriction measures were implemented. On the other hand, the $\mathrm{R}_{\text {Bavaria }}$ was below 1 by mid-March at the latest, according to Nowcasting performed for Bavaria [21]. In Regensburg, infected persons were comparably younger than in Oberpfalz or Bavaria as a whole, such that the age group 21-30 years accounted for the largest share (20\%) and $70 \%$ of cases were below or at the age of 60 . The proportion of patients 70 years or older was considerably lower than in highly affected Tirschenreuth or the whole of Oberpfalz and Bavaria.

Around $15 \%$ of cases were hospitalized in our cohort. There are some discrepancies concerning information on hospitalizations. This may be due to the fact that initial hospitalization was queried about during the first interview, whereas data on overall hospitalizations until 10/2020 of the respective cases are based on hospital reports, which may be incomplete. Nonetheless, most cases were hospitalized initially or were not hospitalized. An almost linear increase in hospitalizations with age can be observed.

The overall secondary attack rate of $9.3 \%$ in Regensburg is based on reported cases and may represent a certain overestimation. The definition of a close contact person was applied quite restrictively, nonetheless infection numbers were decreasing by beginning of April. An almost linear increase in the attack rate with age is consistent with other data [22]. Of course, these data are based on the assumption of linear spreading from known cases, which is certainly debatable for SARS-CoV-2. 
Household members appear to have a higher risk of infection [23]. Among household members, we observed a longer symptom-onset-to-diagnosis interval, which could be due to reduced PCR testing capacity at the beginning of the pandemic.

In the Regensburg outbreak, the CFR of $2.1 \%$ was conspicuously lower than the national or state average. Indeed, a very small proportion of patients died in the age group from 50 to 79 in Regensburg contrasting with a very high number of 50 to 79 years-olds in Tirschenreuth and Oberpfalz. Presumably, a greater proportion of young people and a lower proportion of persons above 70 years of age are responsible for the low CFR in Regensburg. The absence of larger outbreaks in nursing/retirement homes as well as a different distribution of risk factors are likely to be crucial factors in this context. Furthermore, there are a considerable number of tertiary care hospitals in the region, and a number of severe cases treated mainly at the University Hospital did not account for the investigated outbreak as they were often transferred from hospitals of neighbouring districts and had their permanent residence outside the jurisdiction of the Regensburg Public Health Department. Fatalities in the considered period occurred in elderly patients with risk factors, though underreporting is possible. Other biological factors as contributing factors remain unclear.

Of the initial 25 cases in Regensburg, 13 had a history of traveling/skiing (11 in Italy, of which 8 were in Trentino/South Tyrol). Many of the initial cases in Regensburg may have been linked to the Bavarian winter holidays (24/02 to $28 / 02 / 2020$ ) or the skiing season. The absence of a major spreading event, however, may have contributed to lower case numbers and to a lower CFR.

In terms of symptomatology, COVID-19 is heterogeneous [24, 25]. We assessed the initial frequency of symptoms in different age groups as well as the duration of symptoms in follow-up calls. The leading symptom in all age groups was fever. On the other hand, there are more specific, though not pathognomonic symptoms such as odour/taste disorder, which nearly $20 \%$ of cases reported as an initial symptom. Generally, in the very young and the very elderly, certain symptoms such as rhinitis or limb pain are reported less frequently. Remarkably, approximately $9 \%$ of cases interviewed during follow-up reported persisting symptoms for at least 6 weeks from onset.

We also assessed a number of risk factors and their associations with COVID-19 symptoms. Patients taking ACE inhibitors as part of their daily medication had an equal risk of dyspnea and no significant differences in the duration of cough and the general feeling of illness. Smokers reported shorter symptom duration, which might be due to their being habituated to a lower taste quality and smoker's cough in general. Not surprisingly, patients with a BMI $>30 \mathrm{~kg} / \mathrm{m}^{2}$ more frequently reported difficulty breathing. In contrast, the duration of dyspnea was equal across classes of adiposity. The cause of a significantly shorter cough duration in persons with a BMI $>30 \mathrm{~kg} / \mathrm{m}^{2}$ remains unclear. 
The strengths of our study are the almost complete investigation of a large regional cohort with a

279 detailed description and analysis of age-specific symptoms and duration of symptoms.

Study limitations include the retrospective design with potential interviewer bias or recall bias and uncertain validity of the data regarding the type and duration of symptoms. Moreover, the data were collected during the heyday of the pandemic as part of infection control and containment measures, precluding a thorough planning of the interviews because of the pre-existing workload of the public health authorities. Also, the follow-up interview could not be conducted within a fixed time frame for each individual but was performed if at least 6 weeks had passed since the reported onset of symptoms, potentially resulting in variation in the timing of the data collected on symptom duration and state of recovery. The data on symptom duration may not be entirely generalizable because mild cases may have been more likely to be contacted than severe cases. As in other studies relying on reported infections, an uncertain number of a- or oligosymptomatic cases may have been missed.

Furthermore, exposure patterns and testing modalities might have changed during the course of the outbreak, such that hospitalizations were more likely to occur at the beginning of the pandemic even in mild cases, whereas PCR testing was initially more restrictive due to a lack of laboratory capacities.

In conclusion, the Regensburg outbreak was characterized by relatively low numbers of cases and fatalities, particularly in elderly patients and those with COVID-19 risk factors. By comparison, the outbreak affected a relatively large proportion of younger individuals. COVID-19 showed a variety of symptoms and varying symptom duration, some of them lasting for weeks. Further prospective research is needed to clarify and confirm the presented data.

\section{Conflict of interest: None.}

Funding: None.

Acknowledgement: We thank Katharina Katz and Jasmin Metz (both Bavarian Health and Food Safety Authority, LGL) for providing epidemiological data on Bavarian SARS-COV-2 cases. We thank the team of the Regensburg Public Health Department and all supporting colleagues for their unremitting efforts. 


\section{References}

[1] Johns Hopkins University: https://gisanddata.maps.arcgis.com/apps/opsdashboard/index.html\#/bda7594740fd40299423467b4 8e9ecf6. Accessed 10/09/2020

[2] WHO Coronavirus disease (COVID-19) - Weekly Epidemiological Update. 6 September 2020: https://www.who.int/docs/default-source/coronaviruse/situation-reports/20200907-weekly-epiupdate-4.pdf?sfvrsn=f5f607ee_2. Accessed 10/09/2020

[3] Chen N, Zhou M, Dong X, et al. Epidemiological and clinical characteristics of 99 cases of 2019 novel coronavirus pneumonia in Wuhan, China: a descriptive study. Lancet. 2020;395(10223):507513. doi:10.1016/S0140-6736(20)30211-7

[4] Wu Z, McGoogan JM. Characteristics of and Important Lessons from the Coronavirus Disease 2019 (COVID-19) Outbreak in China: Summary of a Report of 72314 Cases from the Chinese Center for Disease Control and Prevention. JAMA - Journal of the American Medical Association. 2020.

[5] Zheng Z, Peng F, Xu B, Zhao J, Liu H, Peng J, Li Q, Jiang C, Zhou Y, Liu S, Ye C, Zhang P, Xing Y, Guo $\mathrm{H}$, Tang W. Risk factors of critical \& mortal COVID-19 cases: A systematic literature review and metaanalysis. J Infect. 2020 Aug;81(2):e16-e25. doi: 10.1016/j.jinf.2020.04.021. Epub 2020 Apr 23. PMID: 32335169; PMCID: PMC7177098.

[6] WHO Coronavirus disease (COVID-19) Situation Report - 198, 5 August 2020; Accessed 10/09/2020: https://www.who.int/docs/default-source/coronaviruse/situation-reports/20200805covid-19-sitrep-198.pdf?sfvrsn=f99d1754_2

[7] RKI Falldefinition Coronavirus-Krankheit-2019 (COVID-19) (SARS-CoV-2):

https://www.rki.de/DE/Content/InfAZ/N/Neuartiges_Coronavirus/Falldefinition.pdf?_blob=publicat ionFile. Accessed 10/09/2020.

[8] RKI Kontaktpersonen-Nachverfolgung bei respiratorischen Erkrankungen durch das Coronavirus SARS-CoV-2 Accessed: 9.9.2020.

https://www.rki.de/DE/Content/InfAZ/N/Neuartiges_Coronavirus/Kontaktperson/Management.html Accessed 10/09/2020

[9] Kabesch M, Roth S, Brandstetter S, et al. Successful containment of Covid-19 outbreak in a large maternity and perinatal center while continuing clinical service [published online ahead of print, 2020 Apr 22]. Pediatr Allergy Immunol. 2020;10.1111/pai.13265. doi:10.1111/pai.13265

[10] Bavarian Health and Food Safety Authority, LGL: Situation report 24/05/2020

[11] Coronavirus Disease 2019 (COVID-19) - Daily Situation Report of the Robert Koch Institute https://www.rki.de/DE/Content/InfAZ/N/Neuartiges_Coronavirus/Situationsberichte/2020-05-24en.pdf?_blob=publicationFile Accessed 10/09/2020

[12] ECDC Communicable disease threats report, 24-30 May 2020, week 22 https://www.ecdc.europa.eu/sites/default/files/documents/Communicable-disease-threats-report30-may-2020.pdf

[13] Coronavirus disease (COVID-19) Situation Report - 125 Data as received by WHO from national authorities by 10:00 CEST, 24 May 2020: https://www.who.int/docs/defaultsource/coronaviruse/situation-reports/20200524-covid-19-sitrep-125.pdf?sfvrsn=80e7d7fo_2 
[14] Landkreis Regensburg in Zahlen. https://www.landkreisregensburg.de/media/36986/20190912_lkr_in_zahlen.pdf

[15] Regensburg in Zahlen. https://www.regensburg.de/fm/121/regensburg-in-zahlen-2019.pdf

[16] Statistik Bayern. https://www.statistik.bayern.de/mam/produkte/veroffentlichungen/statistische_berichte/a1100c_2 01644.pdf. Stand 2016. Accessed 11/09/20

[17] Bevölkerungsstand Deutschland. https://www.destatis.de/DE/Themen/GesellschaftUmwelt/Bevoelkerung/Bevoelkerungsstand/_inhalt.html. Accessed 11/09/2020

[18] Bevölkerungsstand Europa. https://www.destatis.de/Europa/DE/Home/_inhalt.html Accessed $11 / 09 / 2020$

[19] Deutsche Stiftung Weltbevölkerung - Aktueller Bevölkerungsstand. https://www.dsw.org/weltbevoelkerung/?gclid=EAlalQobChMIma3Co7ng6wIVEBd7Ch0i6geQEAAYAS AAEgJ_bPD_BwE. Accessed 11/09/2020

[20] Fu L, Wang B, Yuan T, et al. Clinical characteristics of coronavirus disease 2019 (COVID-19) in China: A systematic review and meta-analysis. J Infect. 2020;80(6):656-665. doi:10.1016/j.jinf.2020.03.041

[21] Guenther F, Bender A, Katz K, Kuechenhoff H, Hoehle M. Nowcasting the COVID-19 Pandemic in Bavaria, medRxiv 2020.06.26.20140210; doi: https://doi.org/10.1101/2020.06.26.20140210; https://corona.stat.uni-muenchen.de/nowcast/

[22] Shah K, Saxena D, Mavalankar D. Secondary Attack Rate of COVID-19 in household contacts: Systematic review. QJM. 2020 Jul 29:hcaa232. doi: 10.1093/qjmed/hcaa232. Epub ahead of print. PMID: 32726452 ; PMCID: PMC7454929.

[23] Jing QL, Liu MJ, Zhang ZB, Fang LQ, Yuan J, Zhang AR, Dean NE, Luo L, Ma MM, Longini I, Kenah E, Lu Y, Ma Y, Jalali N, Yang ZC, Yang Y. Household secondary attack rate of COVID-19 and associated determinants in Guangzhou, China: a retrospective cohort study. Lancet Infect Dis. 2020 Oct;20(10):1141-1150. doi: 10.1016/S1473-3099(20)30471-0. Epub 2020 Jun 17. PMID: 32562601

[24] Pascarella G, Strumia A, Piliego C, Bruno F, Del Buono R, Costa F, Scarlata S, Agrò FE. COVID-19 diagnosis and management: a comprehensive review. J Intern Med. 2020 Aug;288(2):192-206. doi: 10.1111/joim.13091. Epub 2020 May 13. PMID: 32348588; PMCID: PMC7267177.

[25] Baj J, Karakuła-Juchnowicz H, Teresiński G, Buszewicz G, Ciesielka M, Sitarz E, Forma A, Karakuła K, Flieger W, Portincasa P, Maciejewski R. COVID-19: Specific and Non-Specific Clinical Manifestations and Symptoms: The Current State of Knowledge. J Clin Med. 2020 Jun 5;9(6):1753. doi: 10.3390/jcm9061753. PMID: 32516940;

[26] Landkreis Regensburg - Eine Auswahl wichtiger statistischer Daten. https://www.statistik.bayern.de/mam/produkte/statistik_kommunal/2018/09375.pdf 


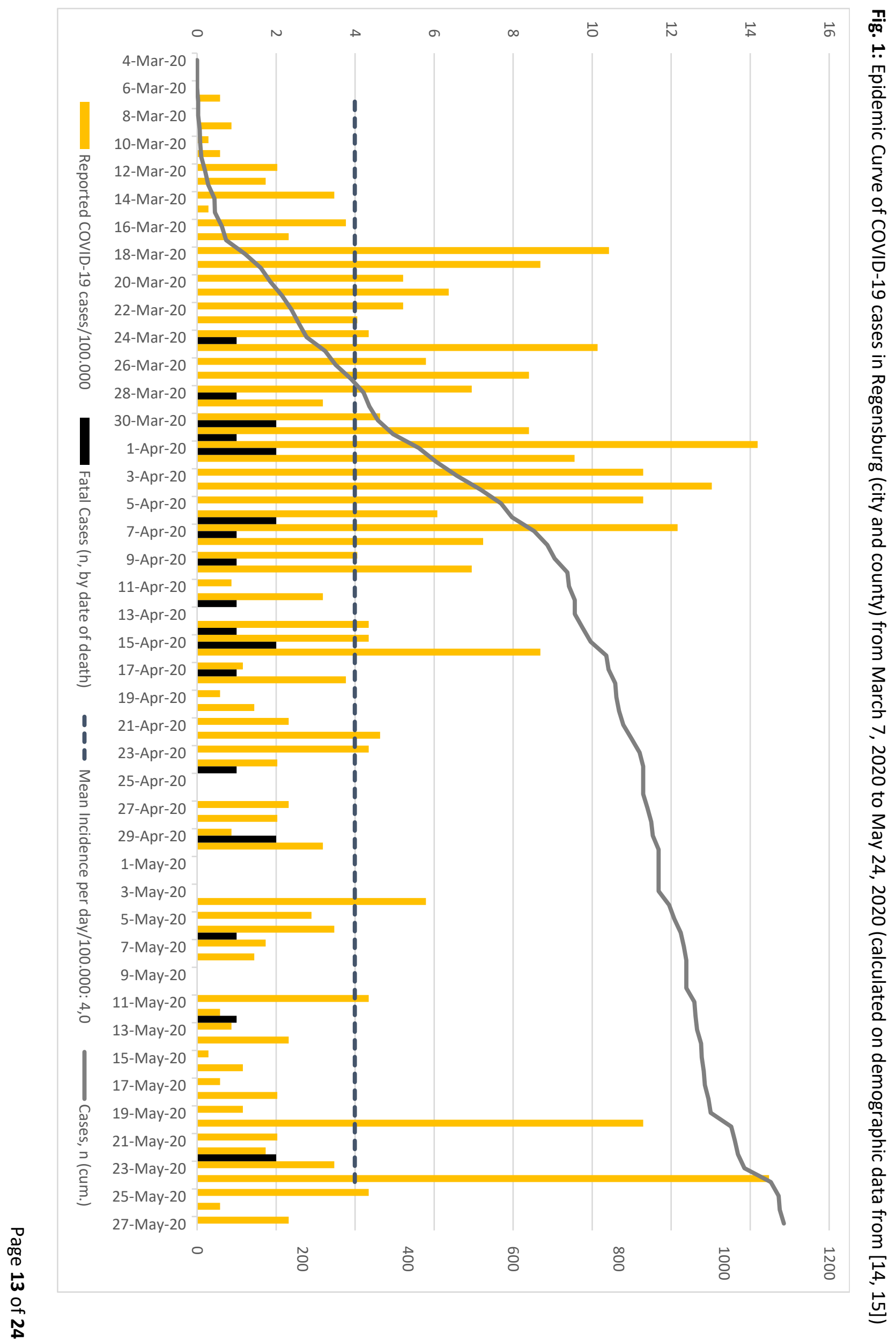


Fig. 2: Age and sex distribution, age-specific attack rates and hospitalisation rates of the Regensburg cases.

390 A: Age and sex distribution of cases (cases per 100.000: approximate calculation according to [26], numbers for the city of Regensburg derived from county 391 numbers under the assumption of an equal age distribution)

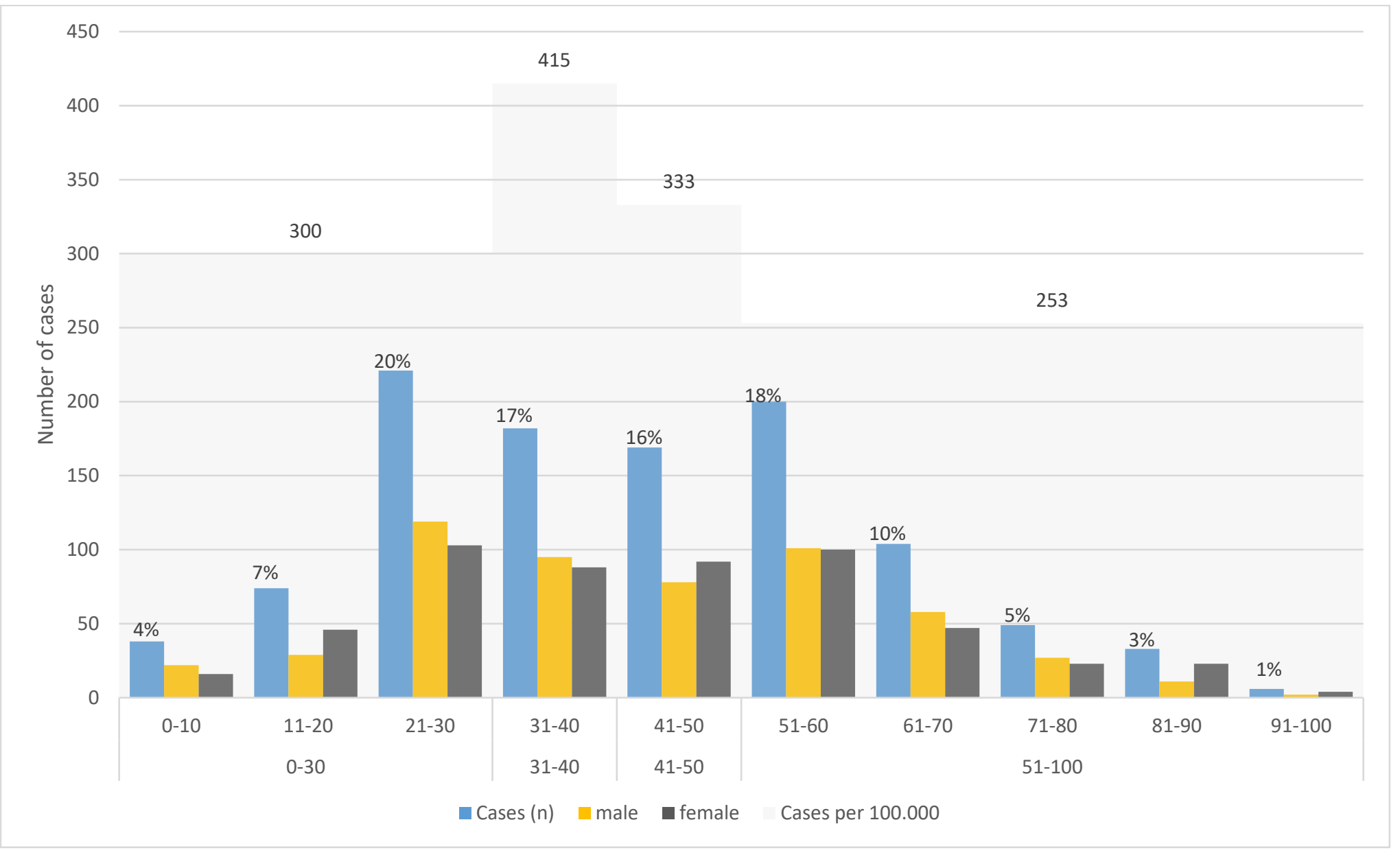


40

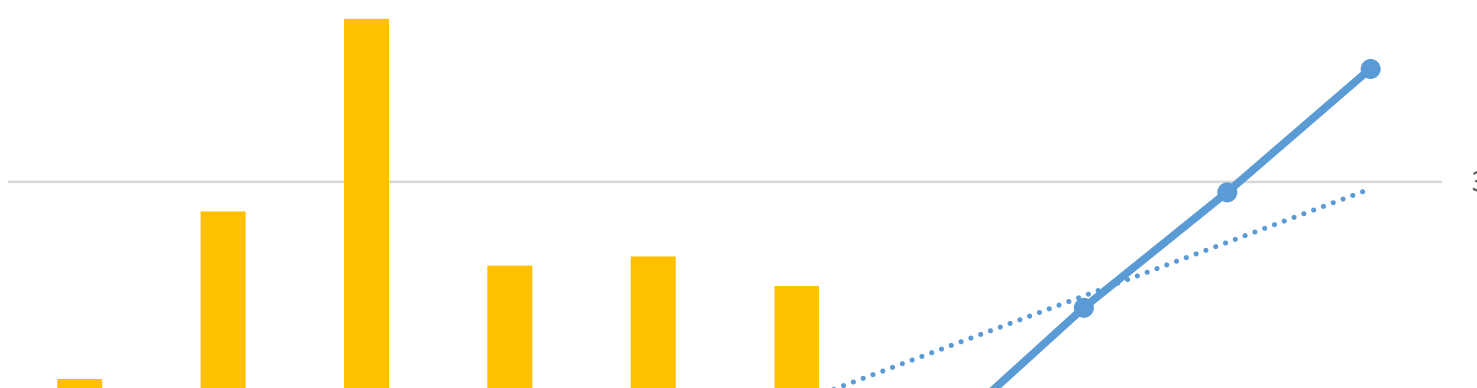

Linear (Attack rate \%)

0

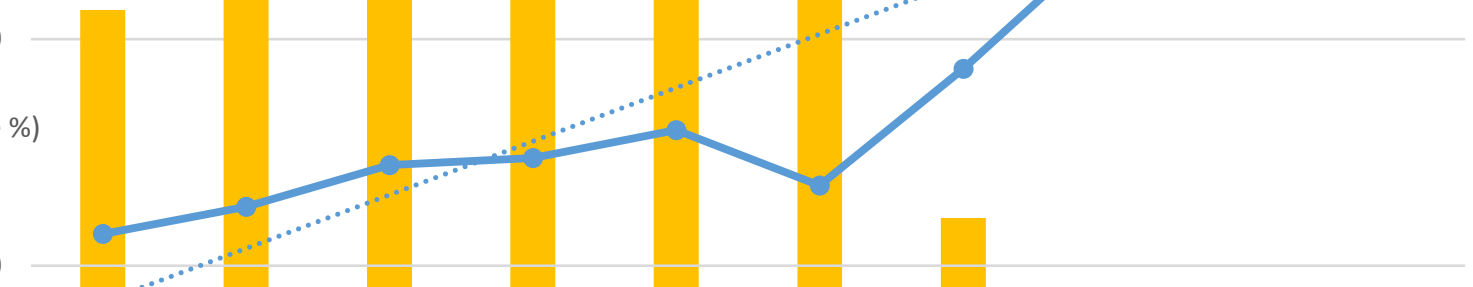

396 
250

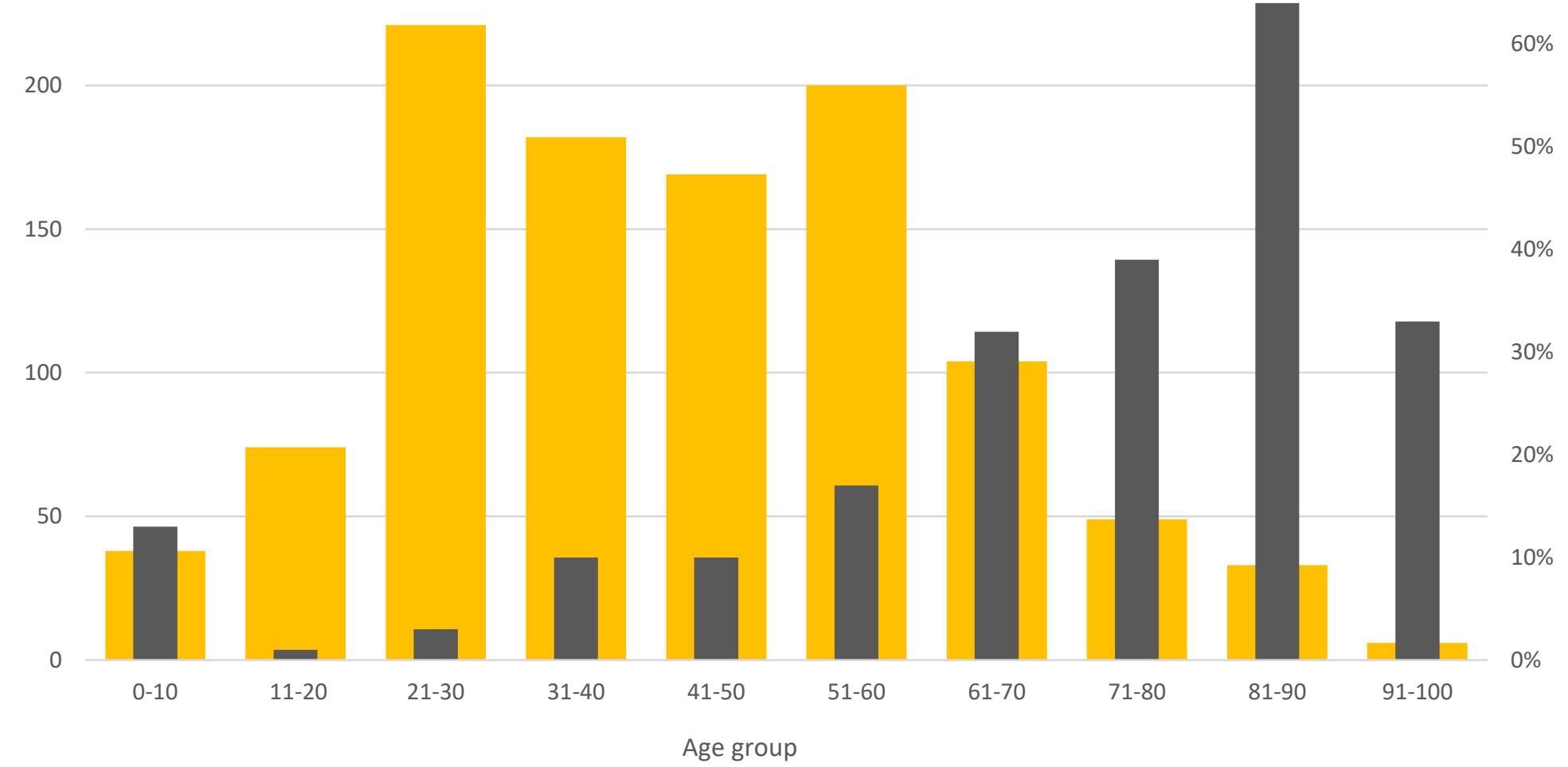




\section{A: Cases per age group (\%)}

$25 \%$

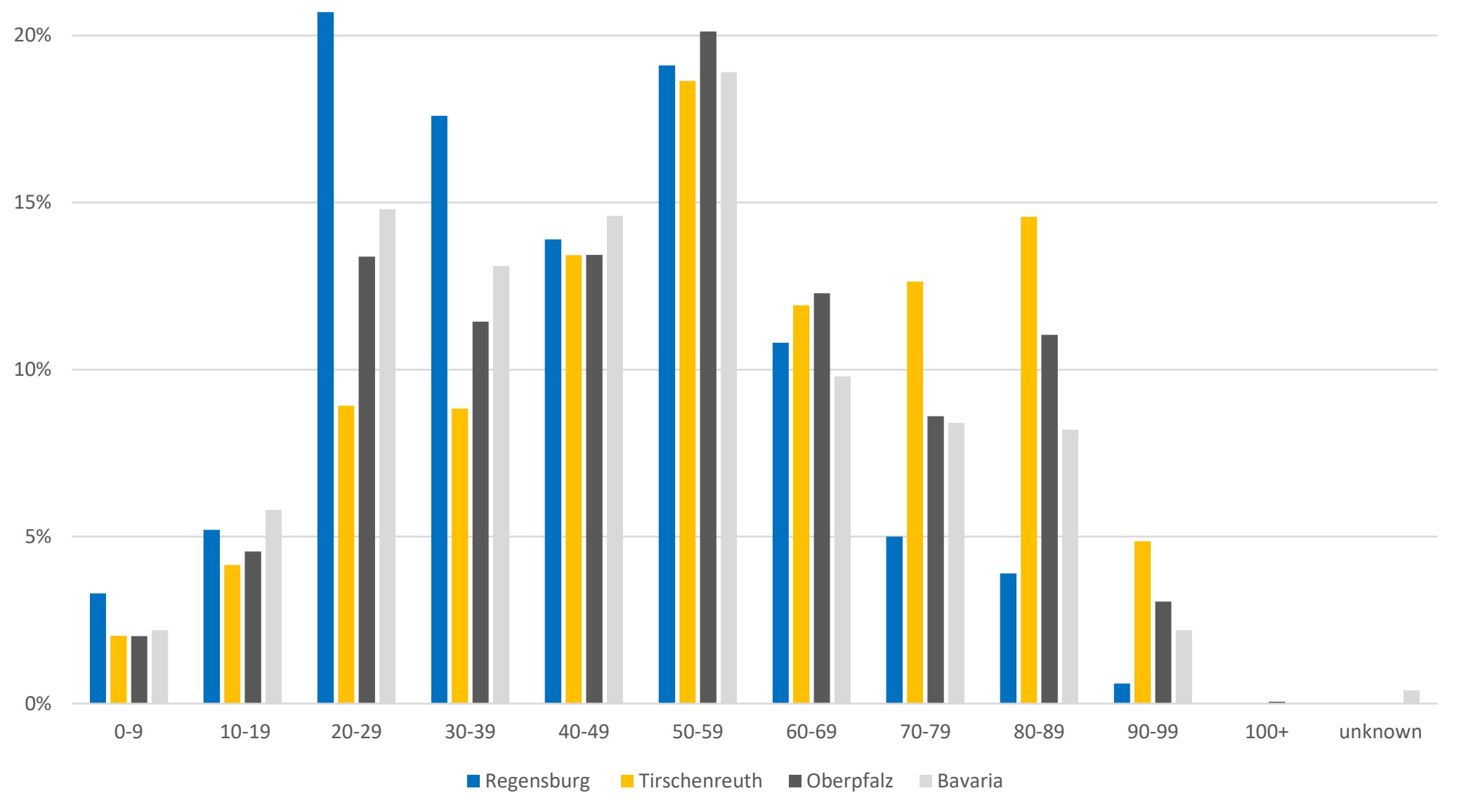




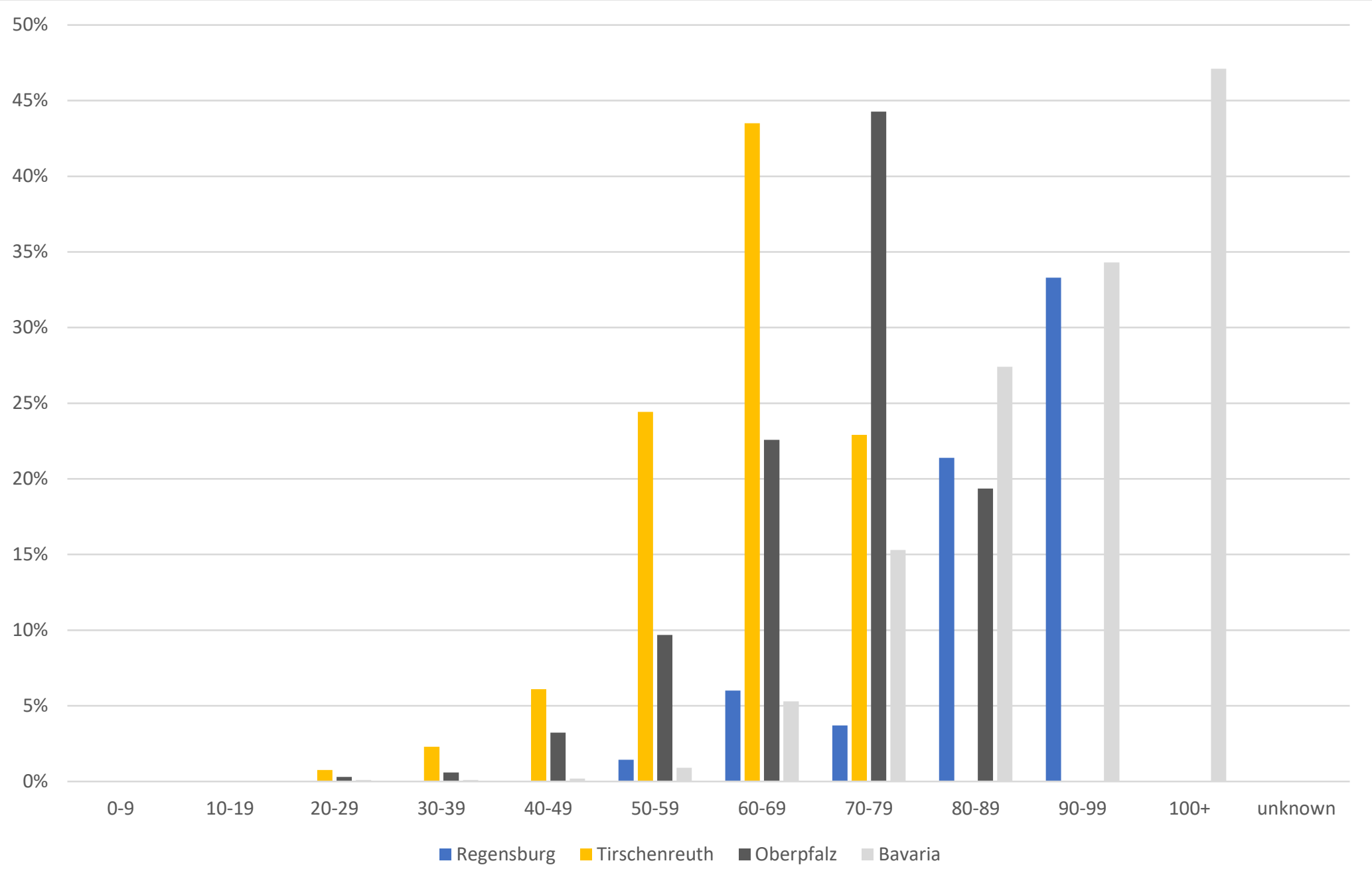

408

409 


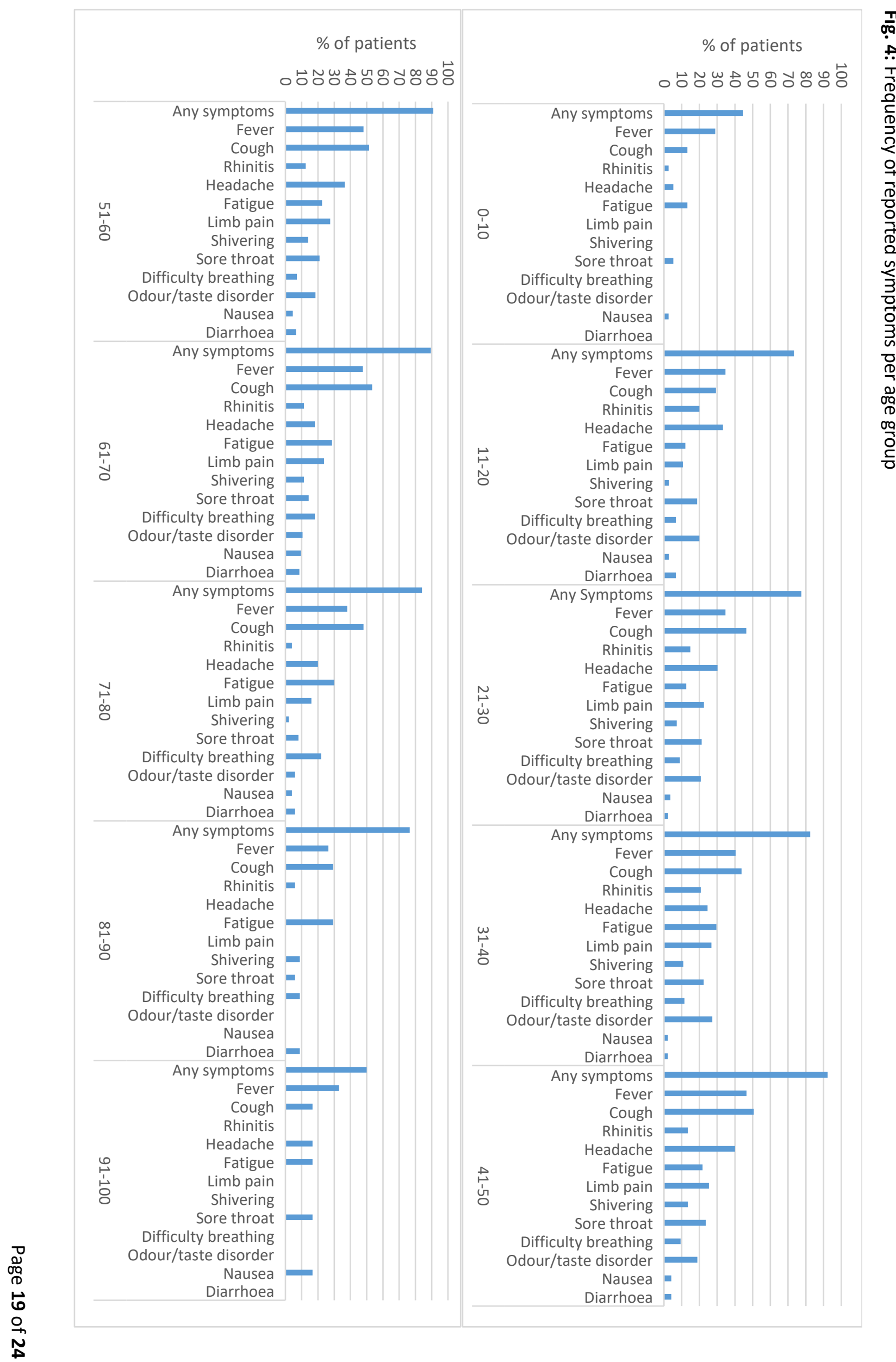


Fig. 5: Frequency, duration and persistence of symptoms

415 A: Duration of symptoms (by order of frequency)

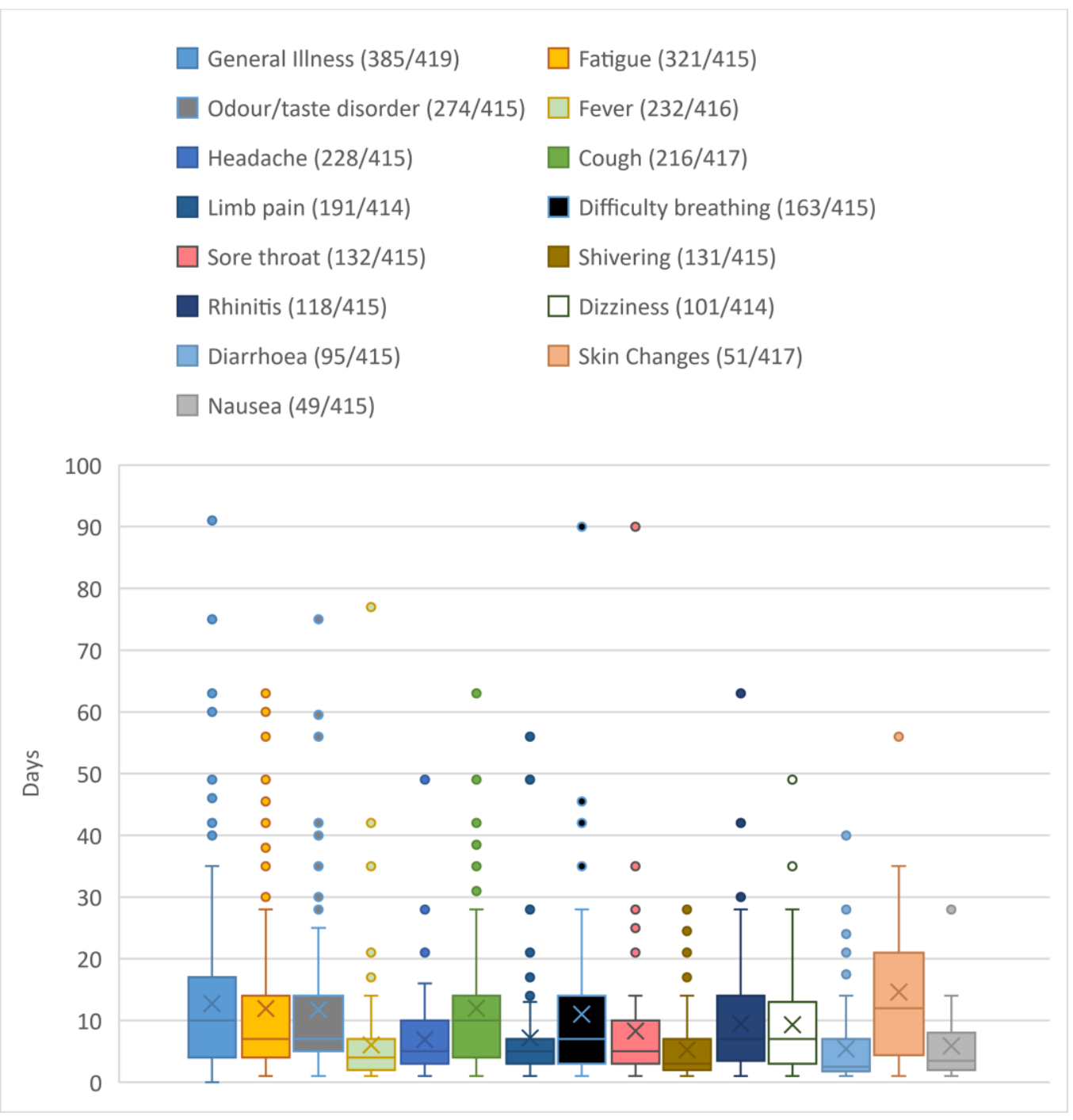




\section{B: Rates of persistent symptoms}

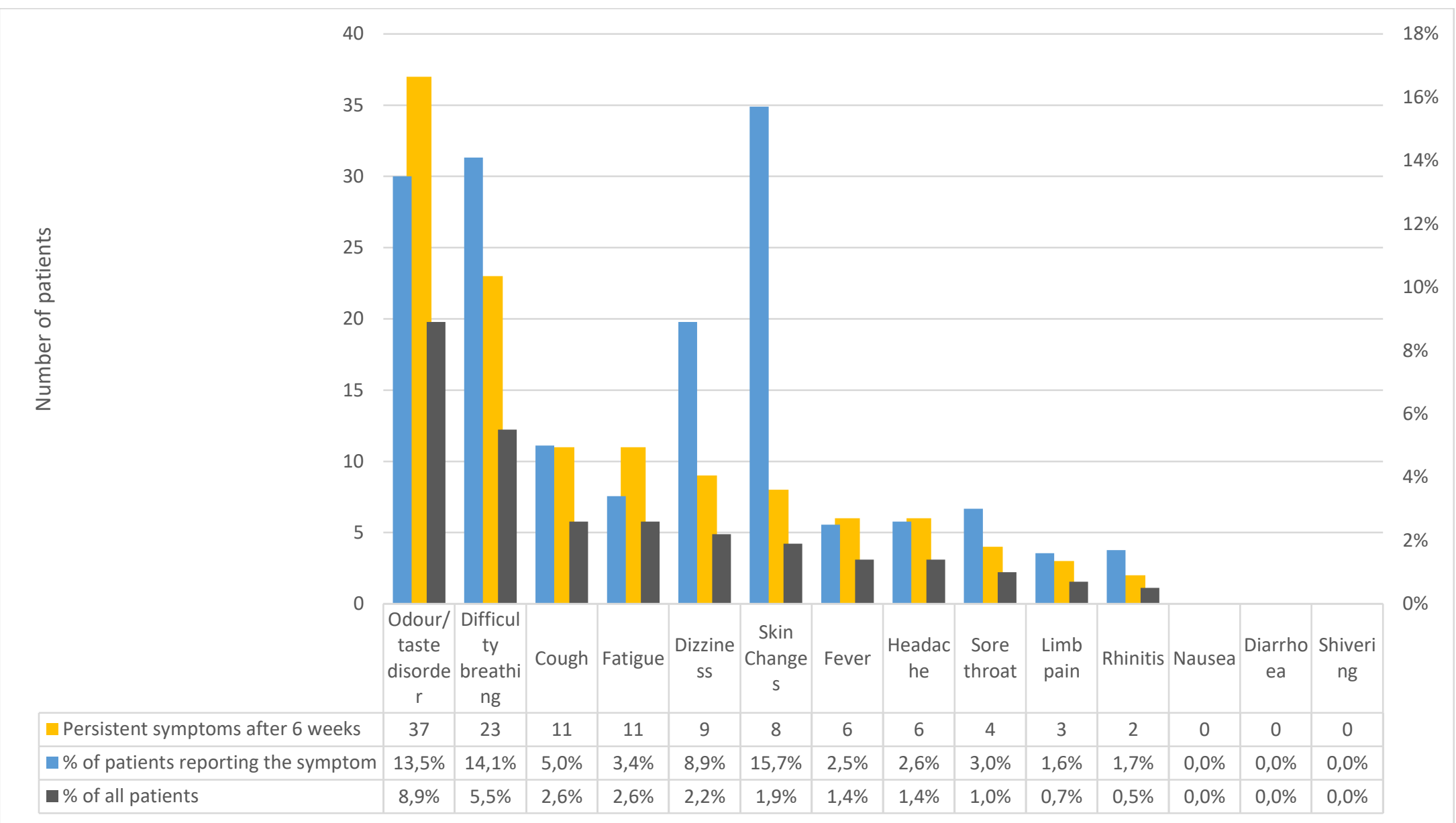

419

420 
422 Table 1: Characteristics of all (left column) and fatal (right column) cases in the Regensburg area

\begin{tabular}{|c|c|c|}
\hline $\mathrm{n}(\%)$ & $1084(100)$ & $23(2,1)$ \\
\hline \multicolumn{3}{|l|}{ Sex } \\
\hline Male [n] (\%) & $542(50)$ & $15(65.2)$ \\
\hline Female $[\mathrm{n}](\%)$ & $542(50)$ & $8(34,8)$ \\
\hline Mean Age [years] & 43,1 & $\mathbf{7 4 , 4}$ \\
\hline \multicolumn{3}{|l|}{ Residence } \\
\hline City [n] (\%) & $643(59,3)$ & $8(34,8)$ \\
\hline District [n] (\%) & $441(40,7)$ & $15(65,2)$ \\
\hline Initially hospitalized & $163(15)$ & $20(87)$ \\
\hline $\begin{array}{l}\text { Duration of disease (onset - } \\
\text { death) [d] }\end{array}$ & - & $\begin{array}{r}\text { Mean: 16,7 (median 12; IQR: } 2- \\
\text { 33; Max.: 59) }\end{array}$ \\
\hline Onset of disease unknown & $142(13,1)$ & $4(17,4)$ \\
\hline \multicolumn{3}{|l|}{ Symptoms initially [n] (\%) } \\
\hline any & $897(82,7)$ & $20(87)$ \\
\hline Cough & $490(45)$ & $12(52,2)$ \\
\hline Fever & $443(41)$ & $8(34,8)$ \\
\hline Headache & $310(29)$ & $0(0)$ \\
\hline Limb pain & $238(22)$ & $1(4,3)$ \\
\hline Fatigue & $210(19)$ & $7(30,4)$ \\
\hline Sore Throat & $208(19)$ & $3(13)$ \\
\hline Odour or taste disorders & $194(18)$ & $1(4,3)$ \\
\hline Rhinitis & $151(14)$ & $1(4,3)$ \\
\hline Difficulty breathing & $109(10)$ & $8(34,8)$ \\
\hline Shivering & $105(10)$ & $1(4,3)$ \\
\hline Diarrhoea & $49(5)$ & $3(13)$ \\
\hline Nausea & $44(4)$ & $1(4,3)$ \\
\hline Exposure & & [n] (\%) \\
\hline Contact with known case & $470(43,4)$ & $5(21,7)$ \\
\hline History of Travel & $107(9,9)$ & $0(0)$ \\
\hline \multicolumn{3}{|l|}{ Living } \\
\hline $\begin{array}{l}\text { with other persons in one } \\
\text { household }\end{array}$ & $800(73,8)$ & $20(87)$ \\
\hline in nursing home & - & $5(21,7)$ \\
\hline Risk factors & & [n] (\%) \\
\hline Overall & $304(28)$ & $20(87)$ \\
\hline Chronic heart disease & $109(10,1)$ & $12(52,2)$ \\
\hline Chronic lung disease & $73(6,7)$ & $5(21,7)$ \\
\hline Diabetes mellitus & $49(4,5)$ & $3(13)$ \\
\hline Chronic kidney disease & $21(1,9)$ & $4(17,4)$ \\
\hline Cancer & $15(1,4)$ & $3(13)$ \\
\hline Immunosuppression & $13(1,2)$ & $2(8,7)$ \\
\hline None & $717(66,1)$ & $3(13)$ \\
\hline
\end{tabular}


Table 2: Comparison of incidence and case fatality rate (calculated on basis of daily situation reports $426[10,11,12,13]$ and demographic data $[14,15,16,17,18,19]$

\begin{tabular}{|l|l|l|}
\hline March 7, 2020 - May 24, 2020 & Cases/100.000 & Case fatality rate (\%) \\
\hline Regensburg (City/county) & 315,4 & 2,1 \\
\hline Oberpfalz & 468,5 & 6,6 \\
\hline Tirschenreuth & 1551,1 & 11,6 \\
\hline Bavaria & 359,7 & 5,1 \\
\hline Germany & 214,3 & 4,6 \\
\hline Europe & 309,1 & 12,3 \\
\hline Worldwide & 69,4 & 6,4 \\
\hline Hubei (by July 31, 2020) & 115,2 & 6,6 \\
\hline
\end{tabular}

427 
Table 3: Risk factors and symptoms

430 A: ACE inhibitors and respiratory symptoms

\begin{tabular}{|l|l|l|l|}
\hline Number of patients & ACE inhibitor group & Non-ACE inhibitor group & RR \\
\hline $\mathbf{n}(\mathbf{\%})$ & $\mathbf{2 1} \mathbf{( 5 , 2 \% )}$ & $\mathbf{3 8 5}(\mathbf{9 4 , 8 \% )}$ & \\
\hline Dyspnoea & $8(38 \%)$ & $155(39,9 \%)$ & 0,95 \\
\hline Cough & $10(47,6 \%)$ & $206(53,5 \%)$ & 0,89 \\
\hline Symptom duration & (median, min-max) & (median, min-max) & $\begin{array}{l}\text { P (Mann-Whitney- } \\
\text { Wilcoxon-Test) }\end{array}$ \\
\hline General illness & $14(0-35) \mathrm{d}$ & $10(0-75) \mathrm{d}$ & $\mathrm{p}=0.306$ \\
\hline Dyspnea & $7(1-28) \mathrm{d}$ & $7(1-90) \mathrm{d}$ & $\mathrm{p}=0.7793$ \\
\hline Cough & $10(3-31) \mathrm{d}$ & $10,5(1-63) \mathrm{d}$ & $\mathrm{p}=0.5412$ \\
\hline
\end{tabular}

431 B: Smoking and respiratory symptoms or odour/taste disorder

\begin{tabular}{|l|l|l|l|}
\hline Number of patients & Smokers & Non-Smokers & RR \\
\hline $\mathbf{n}(\mathbf{\%})$ & $\mathbf{5 0}(\mathbf{1 2 , 0})$ & $\mathbf{3 6 7}(\mathbf{8 7 , 5 \% )}$ & \\
\hline Dyspnoea & $22(44 \%)$ & $141(39 \%)$ & 1,13 \\
\hline Cough & $23(46 \%)$ & $193(53 \%)$ & 0,87 \\
\hline Odour/taste disorder & $31(62 \%)$ & $242(67 \%)$ & 0,93 \\
\hline Symptom duration & (median, min-max) & (median, min-max) & $\begin{array}{l}\text { P (Mann-Whitney- } \\
\text { Wilcoxon-Test) }\end{array}$ \\
\hline General illness & $6(0-31) \mathrm{d}$ & $10(0-91) \mathrm{d}$ & $\mathrm{p}=0.0127$ \\
\hline Dyspnea & $3(1-21) \mathrm{d}$ & $7(1-90) \mathrm{d}$ & $\mathrm{p}=0.0706$ \\
\hline Cough & $7(1-31) \mathrm{d}$ & $10(1-63) \mathrm{d}$ & $\mathrm{p}=0.604$ \\
\hline Odour/taste disorder & $6(2-31) \mathrm{d}$ & $8(1-75) \mathrm{d}$ & $\mathrm{p}=0.0182$ \\
\hline
\end{tabular}

C: BMI and respiratory symptoms

\begin{tabular}{|l|l|l|l|}
\hline Number of patients & BMI > 30 & BMI < 30 & RR \\
\hline $\mathbf{n}(\%)$ & $\mathbf{6 9 ( 1 6 , 7 \% )}$ & $\mathbf{3 4 4}(\mathbf{8 3 , 3} \%)$ & \\
\hline Dyspnoea & $36(54 \%)$ & $124(36 \%)$ & $\mathbf{1 , 5}$ \\
\hline Cough & $42(64 \%)$ & $170(50 \%)$ & $\mathbf{1 , 3}$ \\
\hline $\begin{array}{l}\text { Comparison of symptom } \\
\text { duration }\end{array}$ & (median, min-max) & (median, min-max) & $\begin{array}{l}\text { P (Mann-Whitney- } \\
\text { Wilcoxon-Test) }\end{array}$ \\
\hline General illness & $14(0-63)$ & 10 days (0-91) d & $\mathrm{p}=0.0429$ \\
\hline Dyspnea & $7(1-42) \mathrm{d}$ & $7(1-90) \mathrm{d}$ & $\mathrm{p}=0.9482$ \\
\hline Cough & $9(1-42) \mathrm{d}$ & $10(1-63) \mathrm{d}$ & $\mathrm{p}<0.001$ \\
\hline
\end{tabular}


Figures

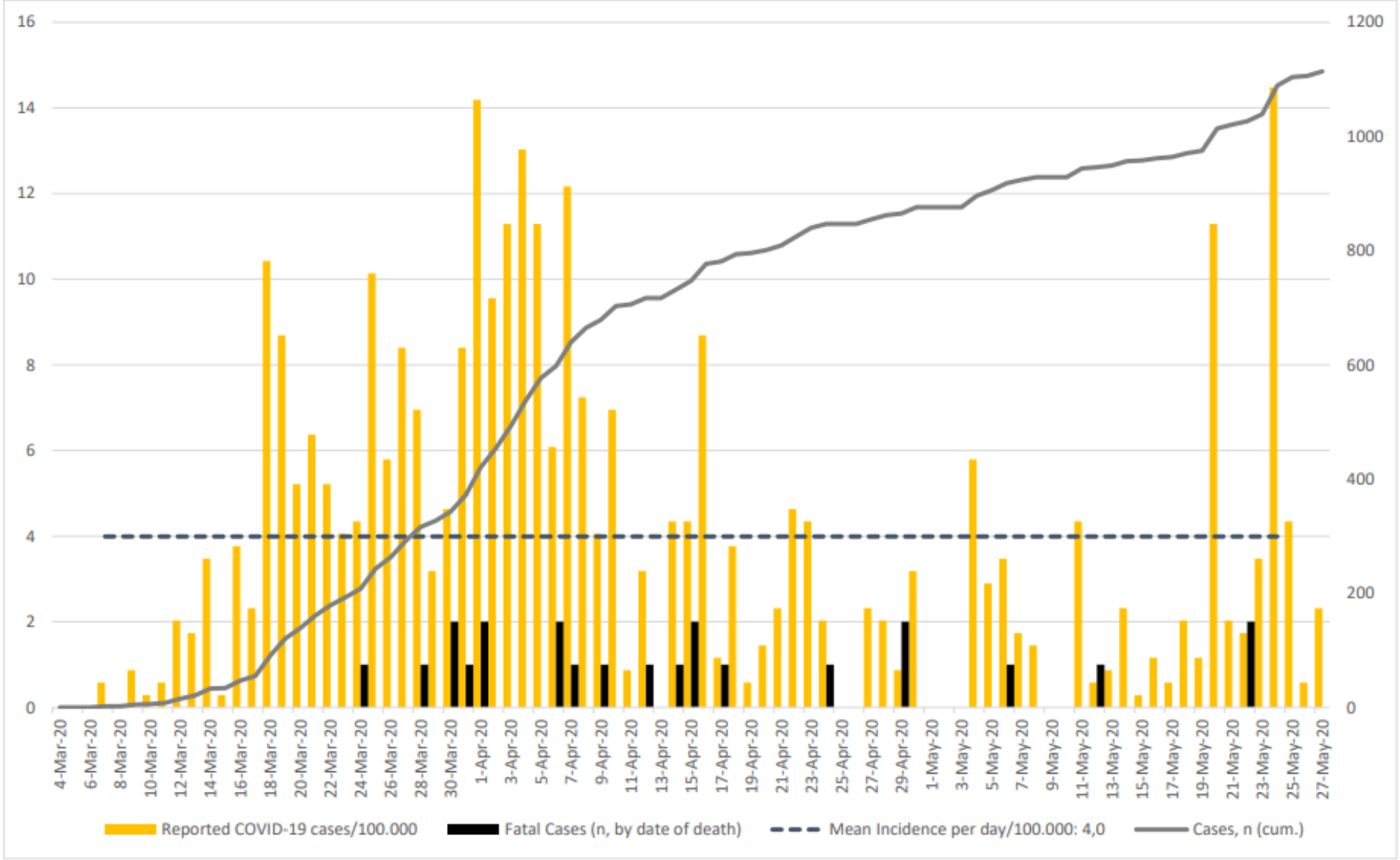

Figure 1

Epidemic Curve of COVID-19 cases in Regensburg (city and county) from March 7, 2020 to May 24, 2020 (calculated on demographic data from $[14,15]$ ) 


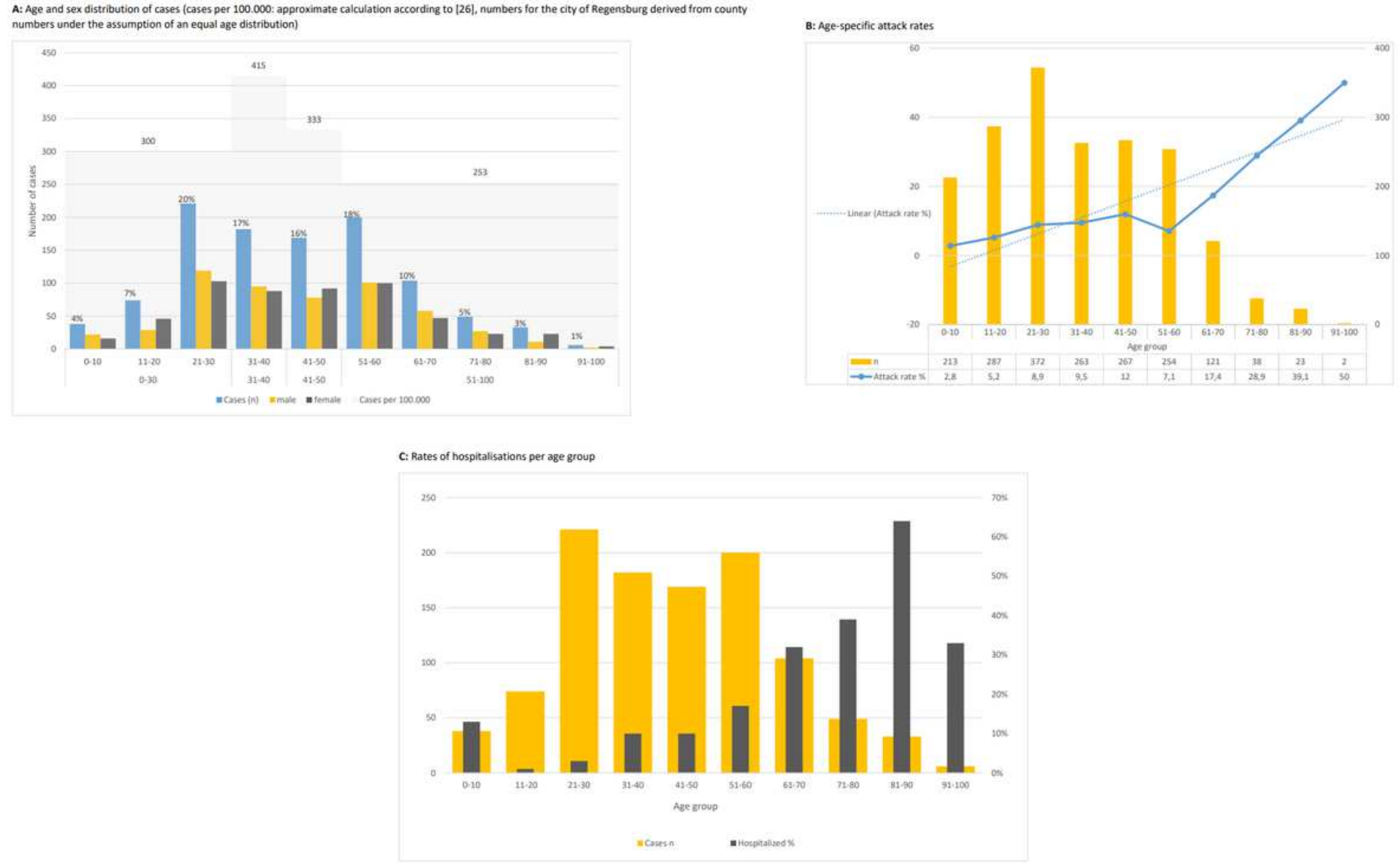

Figure 2

Age and sex distribution, age-specific attack rates and hospitalisation rates of the Regensburg cases. A: Age and sex distribution of cases (cases per 100.000: approximate calculation according to [26], numbers for the city of Regensburg derived from county numbers under the assumption of an equal age distribution). B: Age-specific attack rates. C: Rates of hospitalisations per age group
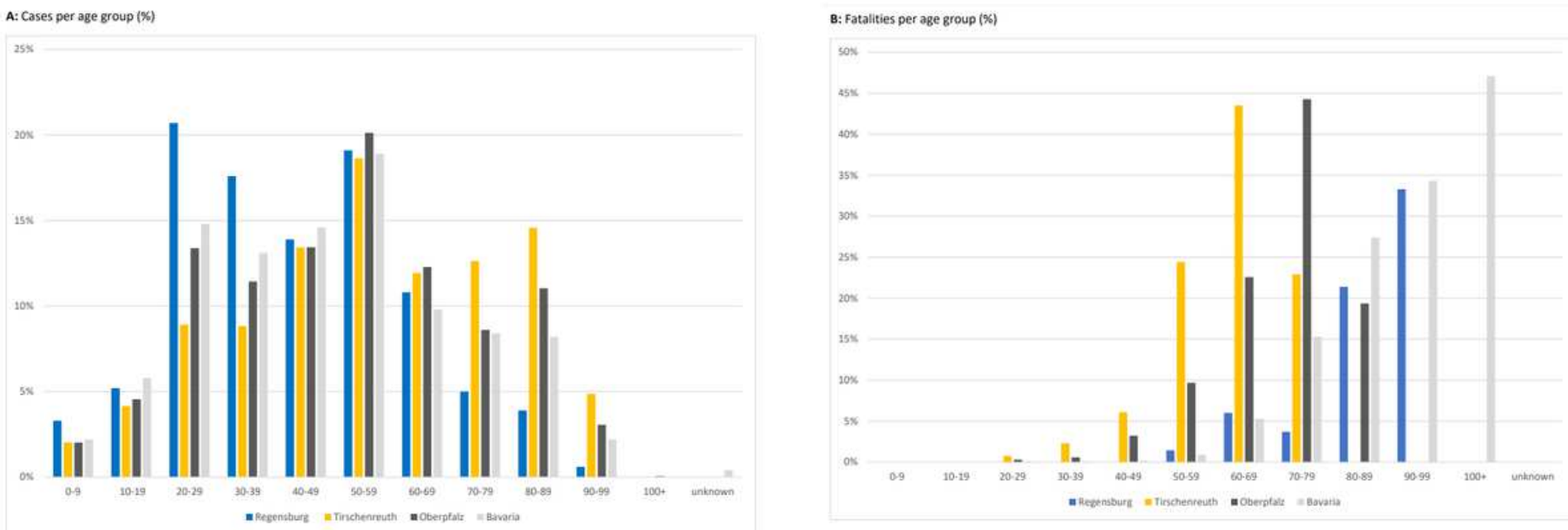

Figure 3 
Comparison of case numbers and fatalities in Regensburg, Tirschenreuth, Oberfpalz and Bavaria. A: Cases per age group (\%). B: Fatalities per age group (\%)

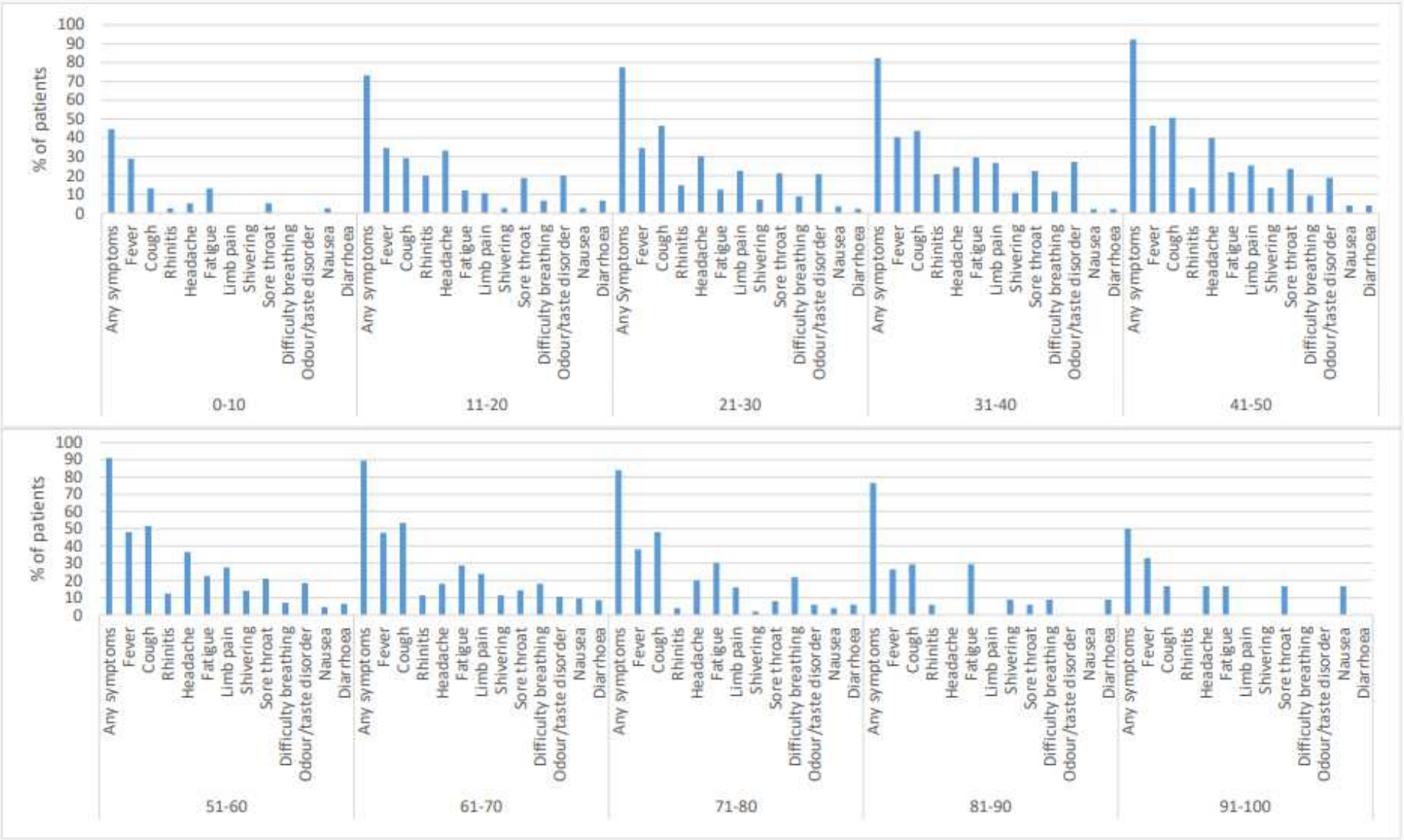

\section{Figure 4}

Frequency of reported symptoms per age Group
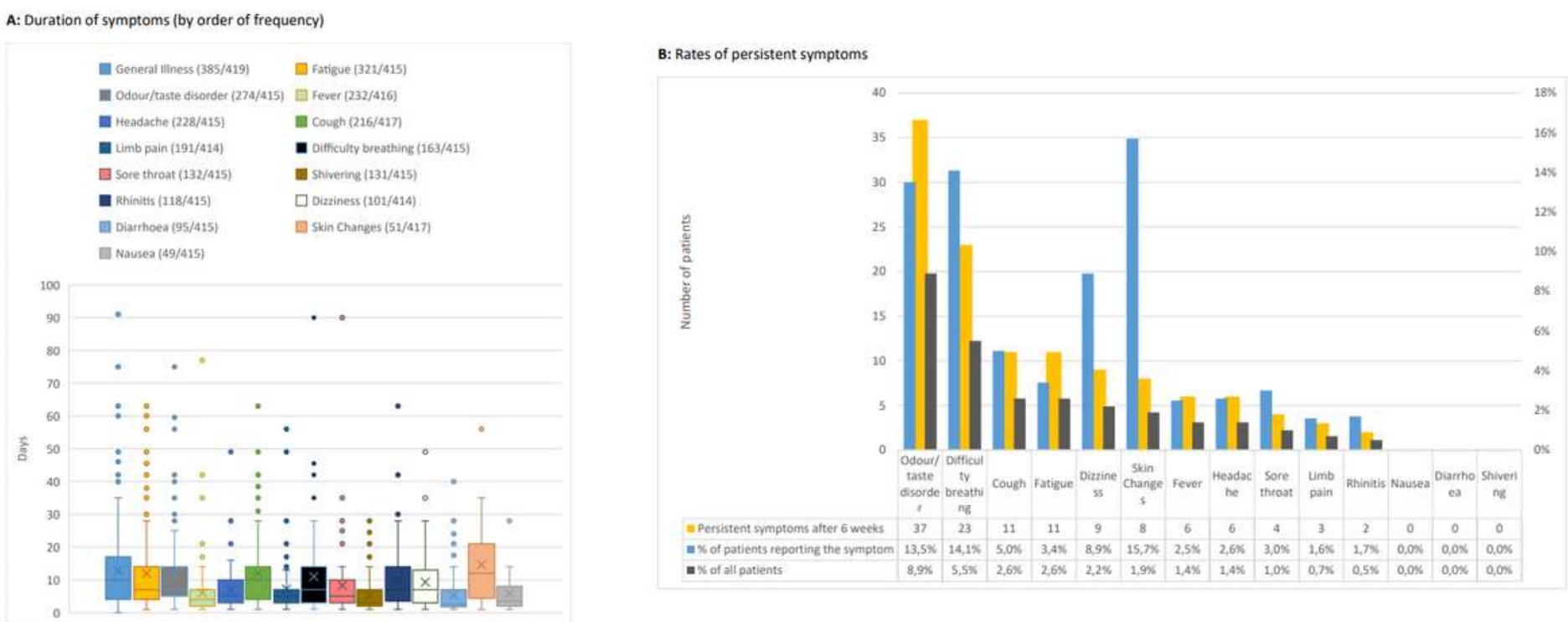

Figure 5 
Frequency, duration and persistence of symptoms. A: Duration of symptoms (by order of frequency). B: Rates of persistent Symptoms 